sciendo

\title{
Vindicating Analyticity \\ Critical Notice of Truth in Virtue of Meaning, by Gillian Russell
}

Manuel García-Carpintero

Universitat de Barcelona

Disputatio Vol. 4, No. 33

November 2012

DOI: 10.2478/disp-2012-0014

ISSN: 0873-626X

(C) 2012 García-Carpintero. Creative Commons Attribution-NonCommercial-NoDerivs 3.0 License 


\title{
Vindicating Analyticity* \\ Critical notice of Truth in Virtue of Meaning, by Gillian Russell
}

\author{
Manuel García-Carpintero \\ Universitat de Barcelona \\ BIBLID [0873-626X (2012) 33; pp. 495-513]
}

\section{Preamble}

In a recent defense of analyticity, Paul Boghossian (1997) mentions the apparent paradox that, even though most philosophers of language today reject the Quinean skepticism about meaning on which it is based, many more appear to share his doubts about the analytic/synthetic divide. ${ }^{1}$ Boghossian himself appears unduly influenced by Quine's criticism, because, while he does vindicate analyticity in an epistemological sense, he coincides with Quine that analyticity in a metaphysical sense - "truth in virtue of meaning" - is not even intelligible. Boghossian's characterization of the two conceptions of analyticity is curiously asymmetric: in the epistemological sense, a statement is analytic "provided that grasp of its meaning alone suffices for justified belief in its truth." In the metaphysical sense, a statement is analytic provided that "it owes its truth value completely to its meaning,

* Financial support for my work was provided by the DGI, Spanish Government, research project FFI2010-16049, and through the award "ICREA Academia" for excellence in research, 2008, funded by the Generalitat de Catalunya; and by the European Community's Seventh Framework Programme FP7/2007-2013 under grant agreement no. 238128. Thanks to Gillian Russell for very useful comments on a previous version that avoided several misunderstandings (even though of course I am responsible for remaining mistakes), to Teresa Marques for her editorial suggestions and to Michael Maudsley for the grammatical revision.

${ }^{1}$ This might have changed meanwhile, perhaps as a result of his article, for, according to the PhilPapers survey (http://philpapers.org/surveys/results.pl), more than $60 \%$ of philosophers favor an analytic-synthetic distinction. Or perhaps that was a misperception, shared in that case with others; cf. also the metasurvey, http://philpapers.org/surveys/metaresults.pl. 
and not at all to 'the facts'” $(1997,334)$ One should have expected a characterization of the latter sense rather along these lines: a statement is analytic provided that facts constitutive of its meaning what it does suffice for, or ground, its truth; after all, there are also facts about meaning, to which analytic statements surely owe their truth. Moreover, a vindication of analyticity in the epistemological sense, one would have thought, should lead immediately to a vindication of it also in a metaphysical sense: if grasp of meaning suffices for justified belief in the truth of a statement, this must surely be because the facts about meaning so grasped are adequately connected with the truth of the statement, so as to provide epistemic justification that it is true.

Be that as it may, Boghossian's criticism of analyticity in the metaphysical sense is compelling, and widely shared by other philosophers; Lycan (1994) and Bonjour (1998), among many others, make similar points. In a nutshell, the criticism goes as follows. The fact that a certain sentence expresses a true proposition is, in a straightforward sense, a matter of linguistic stipulation: to that extent, linguistic assignment of meaning results in truth. But this does not distinguish the truth of some statements (the analytic ones) from that of others (the synthetic ones): all statements owe their truth to linguistic stipulation in that sense. It is quite a different matter whether "the truth or a priori justifiability of the proposition thus expressed is itself somehow a result of such a convention" (Bonjour 1998, p. 54). This cannot be right: the truth-value of a necessary and a priori justifiable proposition cannot depend on our relating it to any particular sentence, nor can its modal or epistemic status; for the straightforward dependence of sentential truth on linguistic stipulation is a contingent and empirical matter.

This work boldly confronts this "two-factor" argument, together with additional ones in the literature, providing answers that at the very least merit consideration by philosophers interested in those topics (all philosophers, one would have said). The proposals are clearly presented, nuanced, and they contemplate in depth the different aspects of the issues, including the most prominent historical ones; thus, before anything else, I unreservedly recommend it to all interested readers. It is also a pleasure to read.

The book has three parts. In the first, the positive view is presented, in three chapters explicating respectively the nature of the "in virtue of" relation, the kinds of meanings to which the account appeals, and related modal matters, topped with a technical appendix 
presenting a Kaplan-style formal system which gives a more precise presentation of the views about meaning on which the account relies. The second part confronts arguments against analyticity, from the perspective of the positive view previously outlined, again in three chapters: one about the arguments in "Two Dogmas"; a second about arguments concerning definition-based analyticity; and a final one on an assorted variety of criticisms: vagueness, indeterminacy of meaning and translation, externalism and others. The final part confronts epistemological matters concerning the kind of justification, if any, offered by analyticity; here the author's views are slightly less developed, though interesting and worth reflecting upon even so. ${ }^{2}$

In what follows, I will discuss some of Russell's claims and raise a few critical points.

\section{Character, sense and reference-determiners}

Russell's central idea to dispose of the two-factor argument against metaphysical analyticity by Boghossian and others outlined above is to distinguish different levels of meaning, something that contemporary philosophy of language, mainly through the work of Kaplan (1989), has already made us familiar with. ${ }^{3}$ The two-factor argument assumes that truth-bearers are propositions, abstract non-linguistic items that have essentially their truth-values with respect to a given world. The argument does show that these are not acceptable candidates for truth in virtue of meaning. However, we can consider other truth-bearers, such as (interpreted) (utterances of) sentences (more about the need for the parenthetical qualifications below); and other aspects of meaning, such as Kaplan's character, which prima facie is a good candidate to account, for instance, for the truth of (English) utterances of

\footnotetext{
${ }^{2}$ It is a pity, especially concerning this last part, that (to all appearances) the book was composed before the impact of Williamson's (2007) forceful objections to analyticity was felt, and so they are not discussed.

${ }^{3}$ Russell grants that all truths, analytic truths included, are not just true in virtue of meaning, but also in virtue of "the world" or "the (non-linguistic) facts". She has a useful discussion of the "in virtue of" relation (pp. 29-37), where she explains that we can nonetheless talk of truth just in virtue of the meaning-factor when the value of the "world"-factor does not make any difference - as in the case of one of the arguments for the multiplication function when the other argument is 0 .
} 
'I am here now'. ${ }^{4}$ Russell, however, like Kaplan and many others, does not think that proper names and natural kind terms have characters like indexicals do - rules that (if everything goes well) determine a referent given features of the context of utterance. She would nevertheless like to count some sentences as analytic in virtue of meaning-features of those expressions - she offers as an example 'Mohammed Ali is Cassius Clay', uttered under the assumption that 'Mohammed Ali' has been introduced "to refer to whatever object, if any, 'Cassius Clay' refers to" (pp. 58-9). ${ }^{5}$

In order to do this, Russell appeals to a meaning-feature which, she contends, coincides with character in the case of indexicals such as 'I', but can be something else in the case of proper names and natural kind terms: a "reference-determiner", which she initially defines as a "condition which an object must meet in order to be the referent of, or fall in the extension of, an expression" (p. 46). According to her, while the referent of an indexical is given by a character-rule relative to a context of utterance, the referent of a proper name (or a natural kind term) is given by a condition such as the bright speck on the horizon on such and such an evening relative to a "context of introduction": the one in which "the word is introduced to the language in the first place".

To develop the suggestion that analyticity is truth in virtue of reference determiner, Russell provides, as a first pass, a modal definition of analyticity (p. 56): a sentence is true in virtue of meaning iff, for all pairs of context of introduction and context of utterance, the proposition it expresses is true with respect to the context of evaluation. Modal definitions such as this are subject to well-known objections which, as Russell correctly points out, appear to be quite general in that they affect a whole variety of them, be they accounts of dispositions, belief, or what have you. In this case, clear counterexamples are "substantive necessities", such as mathematical claims, particularly complex ones (the Continuum Hypothesis or its negation, whatever is true, say). I will discuss the final proposal in the next section, but first

\footnotetext{
${ }^{4}$ This is a point that my colleague Pérez-Otero and I also make in our own defense of metaphysical analyticity (conventional truths, in some cases) against Boghossian and others; cf. García-Carpintero, M. \& Pérez-Otero, M. (2009).

${ }^{5}$ García-Carpintero \& Pérez-Otero (2009, 260-1) discuss similar examples involving proper names and corresponding nicknames, such as 'Robert' and 'Bob' or 'Manuel' and 'Manolo'.
} 
I would like to make a critical point about characters and referencedeterminers, and the bearers of analyticity.

Russell says that "in the case of an indexical such as $I$ " the reference determiner "is part of the meaning", i.e., the character ${ }^{6}$ but I have difficulty in making sense of this. As we have seen, referencedeterminers are by definition conditions that an object must meet to be the referent of an expression. ${ }^{7}$ Now, characters are primarily properties of expression-types; but expression-types such as 'I' are not intended to have referents: only tokens of them (types-incontext) are. Even if the character of the type that a token instantiates is in some sense "part of" the token's reference-determiner, the latter cannot be identified with the former: it goes beyond the character, in that it involves the specific context of instantiation - the token itself, on token-reflexive accounts. ${ }^{8}$

The problem at the root of this perplexity lies with the election of the bearers of analyticity and related properties. If sentences - the official bearers of analyticity in the book - are just types, none of the alleged examples of analyticity would stand even a prima facie chance. Consider 'Mohammed Ali is Cassius Clay'. By choosing this example, as opposed to others which would have served equally - such as 'Manolo is Manuel' (uttered on the assumption that 'Manolo' is intended to refer as a conventional nickname corresponding to the name of the particular Manuel we are talking about) - Russell can easily describe reference-fixing contexts for 'Cassius Clay' and 'Mohammed Ali' immediately suggesting to the audience a particular interpretation, unlike 'Manuel', and thus she can spare herself a qualification such as the one I just made about the interpretation of the case of 'Manuel' on which that of the case of 'Manolo' depends.'

${ }^{6}$ Cf. also p. 156 , and fn. 18 below.

${ }^{7}$ This initial definition is modified later (p. 98), with the aim of excluding circular and derived conditions, but this does not affect the points I will make.

${ }^{8}$ García-Carpintero (1998) defends token-reflexive accounts of indexicals and demonstratives from Kaplan's criticism. In general, Russell appears to share Kaplan's penchant for abstract semantics free from the vagaries of messy psychological facts, but I do not think truth-conditional semantics can survive that (cf. footnote 10 ), nor that it is necessary in order to motivate a mathematically precise formal system.

9 "We'll stipulate, in order to have a clear example, that the name Cassius Clay was introduced when Cassius Clay's parents baptized him (Let's call him (pointing) 
But, of course, there are, or might be, many people called 'Cassius Clay', and the reference-determiner for 'Ali' in the example Russell would like to count as analytic depends as much on just a concrete interpretation (which her reference-fixing stipulations provide) as in the 'Manolo' example. Hence it must at most be sentences taken under specific interpretations, i.e., taking relative to a concrete reference-fixer that are or aren't analytic.

Now, in the case of indexicals, it is only sentences-in-context, or utterances, whose referential expressions have referents and, therefore, which as a whole have contents. ${ }^{10}$ Russell grants an objection that, in effect, proper names show that reference determiners are not meanings, even if they are constrained by meanings (p. 67); but the point applies to all reference-determiners, not just those of proper names. ${ }^{11}$ If we consider demonstratives such as 'here', the point is clear (but I think it applies also to "pure indexicals" such as 'I', 'now',

'Cassius Clay'.) The referent of Mohammed Ali was introduced in a slightly different way, when Elijah Muhammad, the leader of the Nation of Islam, said Let's use 'Mohammed Ali' to name Cassius Clay. Mohammed Ali thus refers to whatever object, if any, Cassius Clay refers to.” (p. 58-9).

${ }^{10}$ Russell will say, I assume (cf. also fn. 20) that indexical sentences have a semantic property, character, so that 'I am here now' - even if, as a sentence-type, it is not properly called true or false, nor the expressions 'I', 'here' and 'now' in it properly ascribed a referent - has the interesting property of being "true whenever uttered" - true in virtue of character; and that it is this that she takes analyticity to be. But then, she should not assimilate 'Mohammed Ali is Cassius Clay' to it; this sentence is not true no matter what the "context of introduction" is: as indicated in the main text, we have to fix a specific interpretation of 'Cassius Clay', with a particular "reference-determiner", for that to be plausible. I suggest below in the main text to put aside Kaplan's notion of the sentence-type 'I am here now' being true whenever uttered, and consider instead the property of an utterance of that sentence (which does have a truth value, and whose referential expressions do have referents and therefore reference-determiners) of having a necessary diagonal. It is the latter notion that is required to assimilate to it 'Mohammed Ali is Cassius Clay'. A related issue is whether we would then need "contexts of introduction", or we may do, as I suggest below in the main text, with contexts of utterance.

${ }^{11}$ She thinks fully-fledged reference-determiners belong in the "metasemantics", not the semantics proper. I do not think that is the proper classification, but, be that as it may, when the point is generalized to indexicals as suggested below, it shows as many researchers have claimed - that the semantics proper gives us less in the way of fully-fledged truth-conditions than some philosophers still think (cf. GarcíaCarpintero 2006a). 
'here' or 'today'). In offering her pet example, 'I am here now', Russell alludes to the problem posed by true instances of 'I am not here now' uttered by recording machines, etc (p. 22), disregarding it for the sake of easy exposition. Let us suppose that we account for these cases by thinking of utterances as "utterance bombs" (Egan 2009): the speaker arranges for an utterance relative to which indexicals are to be interpreted to be "detonated" in her absence. ${ }^{12}$ I think that, on the basis of an account of analyticity along the lines of Russell's based on "reference-determiners", it is still justified to count more ordinary utterances of 'I am here now' as analytic; so I think it is acceptable for her to put aside those cases. But they do make it more glaringly obvious that it is not just the linguistic meaning, or character, of the indexicals that is doing the relevant "referencefixing" job, but also contextual features including the intentions of the speaker: it is not just any utterance of the type that is analytic, but only some of them, in virtue of properties of the utterances that (to put it in psychological terms) speakers do not access just thanks to their core "language faculty", but deploying their full "intentionalconceptual" capacities.

Once we are clear about this, I think we can obtain a simplification of Russell's proposal - even if one she would not accept. ${ }^{13}$ I understand that Russell is convinced by Millian considerations concerning the working of proper names, but some writers have forcefully defended "causal descriptivist" accounts that would make a natural fit with her proposal. ${ }^{14}$ On the version that I prefer, causalcommunication chains individuate proper names: different chain, different (interpreted) word-type, in that they rely on independent introductory conventions. ${ }^{15}$ Each different proper name has a differ-

${ }^{12}$ Other accounts of these cases would allow me to make the same points, mutatis mutandis.

${ }^{13}$ Apparently others have made similar suggestions to her previously, and she declares not to like them (p. 114). I am not at all convinced by the reasons she provides, as I will explain below.

${ }^{14}$ I myself have defended such approaches cf. García-Carpintero (2000 and 2006b).

${ }^{15}$ Madagascar-like cases only show that the "initial baptisms" creating a communication chain and thus contributing to the individuation of names might be inadvertent; cf. Sainsbury 2005, 119-122). 
ent character-like meaning; the character is a rule that assigns to any given token the object - if any - responsible for the initiation of the communication chain. Such a character might include specific information, such as that the object is whatever 'Cassius Clay' refers to, or a bright speck in such-and-such a position on the evening horizon. This will not sensibly be considered part of the "semantics" of the language. ${ }^{16}$ But this will be as little an obstacle to the analyticity of some utterances of 'Mohammed Ali is Cassius Clay' as it was in the case of 'I am here now': the case of indexicals already establishes that (a) only constituents of utterances have reference-determiners, (b) only utterances are analytic or otherwise, and (c) it is not just the semantics proper that accounts for it, but contextually idiosyncratic features too.

There are epistemological issues about this which are related to the phenomenon of semantic deference: we may regard speakers who ignore the dependence of 'Mohammed Ali' on 'Cassius Clay as nonetheless competent. Among other possibilities, this can be handled by distinguishing semantic competence in the ordinary sense - which admits of deference-based understanding for an indefinite number of expressions, to the extent that one fully understand others and knows oneself to be part of a linguistic community - from full competence, which requires knowledge of the reference-determiner. ${ }^{17}$ The interesting epistemological consequences of analyticity, to be discussed in the final section, would require the latter, and thus (as with almost any other form of a priori knowledge discussed in the literature) would fully obtain only under ideal circumstances.

Russell criticizes the "identification of contexts of introduction with contexts of utterance" in such a proposal, but I do not find her reasons convincing. The first is that "it is hard to believe that the reference determiner for a name somehow gets to be sensitive to the context in which the name is uttered, especially when speakers generally don't know the reference determiners for the names they use"

${ }^{16}$ In the case of proper names, only very general features such as that they are referential expressions that behave in the outlined way can be plausibly considered part of the semantics proper, and in that sense it is I think correct to say that specific proper names are not "part of the language".

${ }^{17}$ Russell herself suggests something like this for general terms, pp. 206-7; but I expect she would reject any such view of semantic competence for names, in favor of a Millian view. 
(p. 115). This is to a certain extent correct, in view of the already mentioned phenomenon of semantic deference. But I do not think it matters, for the proposal we are considering will assign competent speakers tacit knowledge of the causal-historical mechanism fixing the reference of proper names, so that they do tacitly know at least that the referent of a given token of a proper name uttered in a context is the object, if any, present in the "initial baptism" starting the chain leading to that token, even if they have no further details of that baptism; to that extent, they do know that "the reference determiner for a name somehow gets to be sensitive to the context in which the name is uttered".

The second criticism relies on a version of the Twin Earth thought experiment in which Twin Earth is not a counterfactual Earth but a distant planet. She correctly points out that the intuition to be accounted for is that our own uses of 'water' there, or relative to it, would still refer to $\mathrm{H}_{2} \mathrm{O}$, not to $\mathrm{XYZ}$, and she contends that this disqualifies the proposal: "it follows that the reference determiner for water is not sensitive to the context of utterance - if it were, water would have to pick out XYZ” (p. 116). But here Russell is assuming an excessively coarse understanding of what a context of utterance is. It is only in an irrelevant sense that Twin Earth is the "context of utterance" in this case: it just happens to be the place in which the utterance takes place. But such a place need not even be the place of the context required to interpret utterances of 'here', if uttered demonstratively pointing to a place in a map, say. The relevant feature of the context of utterance to interpret a use of a proper name or a natural kind term includes the causal chain of communication leading to the use of the name or term in the context - in this case the one brought with him by the speaker from his acquisition of the term on Earth.

Russell's first-stab modal definition of analyticity mentioned above assumes that it is sentences, not utterances, that are bearers of the property. However, there is an analogous property of utterances, namely, the necessity of the (relevant) corresponding diagonal proposition (García-Carpintero 2006b). No matter what one thinks of this alternative proposal, it is I think useful to realize that different contemporary theories of Fregean sense or so-called primary intensions understand those notions in ways that do not differ significantly from reference-determiners, understood as possessing features (a)-(c) a few paragraphs back, and are not exposed to the objections I have 
raised. An account of analyticity in virtue of reference-determiners generalized along the lines suggested should make predications such as 'she is female' or 'Hesperus is visible in the evening' analytic as well - at least putting aside qualms about the existence of the intended referents. ${ }^{18}$ Thus, even if I have found problematic features in Russell's core suggestions about analyticity concerning the bearers of the property and the distinction between contexts of introduction and contexts of utterance, I do think they point in the right direction. But now we have to confront the problems already mentioned for the initial modal characterization, which would equally affect an account in terms of diagonal propositions.

\section{Metaphysical analyticity as containment and exclusion}

Russell usefully relates the problems of the initial modal characterization of analyticity to problems for other modal characterizations of notions such as content, character or direct reference; accounts in terms of modal constancy, such as the rigidity account of direct reference, fail to capture these notions, because they apply to entities which intuitively do not have them ('the even number' or 'the actual inventor of the zip' are rigid, but not directly referential). Directly referential expressions are rigid, but not all rigid expressions are directly referential; we could say that it is direct reference that explains rigidity in some cases, but rigidity cannot in any way account for direct reference. She purports to provide a characterization of analyticity that stands to the one in terms of modal constancy given above as the fundamental idea of direct reference - contributing an object to the proposition - stands to attempts at characterizing it in terms of rigidity (p. 82). This is another of the many valuable suggestions in the book.

Her proposal is inspired by the traditional Kantian notion of analyticity as containment of the predicate-concept in the subject-concept, capable of standing up to the influential Fregean criticism that there are sentences that should have the same property as those that are the

\footnotetext{
${ }^{18}$ Russell appears to assume a Fregean neutral free logic, on which all sentences including vacuous referring expressions (including, say, if Vulcan exists, Vulcan is identical to itself') are neither true nor false (p. 64). I do not think this is the best option; but this is another matter for which she does not provide an explicit justification of her assumptions, so I cannot go into it any further.
} 
model for this view ('bodies are extended'), which cannot be accounted for by dividing them into subject-concept and predicateconcept in any plausible way. In order to do that, she assumes that there are objective ways of ascribing logical forms to sentences, distinguishing in them "parts" such as "logical modifiers", "logical subjects" and "logical predicates". Let us grant this, although once again a more extended discussion should have been provided than the one we actually get, explaining how these notions fit with contemporary linguistics. Also, Russell grants to the Fregean objection that containment of the reference-determiner for the predicate in the determiner for the subject would not account for all cases of analyticity; to account for the analyticity of 'no bachelor is married', we need to appeal also to a relation of exclusion among reference-determiners (p. 95). Finally, she wants to extend the account from the analyticity of truth to that of validity, at least in some cases of the basic schemes in Gentzen-like natural deduction calculi - such as Modus Ponens, Conjunction Elimination or Universal Quantifier Instantiation (101-2) which other writers, starting with Gentzen himself, have considered meaning-constitutive for the logical constants.

I have strong misgivings about Russell's proposals here, even though I admire her resolve in tackling them head-on - i.e., purporting to be as informative as possible about how meaning, understood as so far discussed, grounds the truth of analytic statements, given that a modal account of this will not do. I have two relatively minor reservations and a major one. Firstly, although she alludes to contemporary linguistics to validate the objectivity of her grammatical parsings of sentences - and this is as it should be - it is not at all clear to me that any contemporary linguistic theory would validate decisions that are essential for her account to work in some cases, such as taking the connective 'if ... then' to be the "modifier" in sentences of the form if $S$ then $S$, with the sentence $S$ being first the logical subject and then the logical predicate, or 'having less money than' the modifier and the pair 'poor people', 'rich people' the logical subject and logical predicate in 'poor people have less money than rich people'. This is one more crucial juncture at which Russell's option of ignoring the complexities of a full-fledged account is unfortunate. Secondly, even granting her decisions about logical form, I do not think she provides a full reply to the Fregean objection to accounts in the spirit of Kant's like hers. For instance, I cannot see how instances of excluded middle are accounted for in her proposal; but I think she 
would concur that a proper account of analyticity should include in the category instances of excluded middle and other fundamental logical principles as well as 'bachelors are married men'.

Worrying as these two objections are, there is an even more decisive one. The main problem is, I think, that the crucial notions to which the account appeals - relations of containment and exclusion among reference-determiners - are, if undefined, merely figurative, and therefore cannot do any proper explanatory work. By way of further elucidation beyond the pre-theoretical metaphorical understanding, Russell relates those notions to modal features (pp. 93-5), so that this is, in effect, the most that we do properly understand. What is it for the reference-determiner of an instance of a universal generalization to be contained in the reference-determiner of the universal generalization? The only thing I feel I decently understand by this is the modal characterization, that the former would be true in circumstances determined by any pair of context of utterance and introduction relative to which the latter is true. The same applies, mutatis mutandis, to relations of exclusion among reference determiners. Thus, ultimately Russell's proposal does not provide any proper explanation beyond that provided by the modal account; and she herself has already shown that to be insufficient, on account of the already mentioned general insufficiencies of those accounts. Hence, I do not think she really meets her goal of providing an account that stands to modal constancy as direct reference stands to rigidity.

So, what can the friend of analyticity do, as an alternative? At a general level, I think we cannot say much more than Fine (1994) suggests, i.e., that analyticity is truth of an interpreted item in virtue of the essence of some of its constituents meanings (after having clarified along the lines that Russell does, or the variation I have defended in the first section, what sort of meanings we are appealing to here); this assumes Fine's view that the general failures of modal accounts that Russell points out result in general from misconceived attempts at explaining essence in terms of its mere modal consequences. This is to be elaborated in a more specific detail on a caseby-case basis, explaining in particular cases how it is that the nature of the relevant aspects of the meanings of some expressions, combined 
with the relevant features of others, fixes the truth-value of the sentences in which they occur. ${ }^{19}$

\section{Ephemeral analyticities}

Russell contends that Kripkean views on proper names and natural kind terms allow us to make sense of Quine's claims about the ephemeral or transient character of definition-based analyticities. She grants that this is so in some cases, although it just shows that the relevant cases were not analytic in the first place; real analyticities are not transient or ephemeral. My problems with her discussion here are connected with points about character and reference-fixers I already made in the first section. ${ }^{20}$

She provides as an example "a case where we legislatively introduce a name 'Sam' using the following object-language referencefixing definition: Sam is the tallest boy in the class" (154). Let as call this reference-fixing stipulation ' $\mathrm{Sam}_{\mathrm{RF}}$ '. Russell makes a series of claims about this case which she says "we learnt from Kripke" - claims that, she contends, can also be made about related cases for natural kind terms, such as 'water falls from the sky' - that I find very confusing. One that I do not dispute has to do with the possibility of competent uses of 'Sam' by speakers who are unaware of the refer-

\footnotetext{
${ }^{19}$ This is the strategy García-Carpintero \& Pérez-Otero (2009) recommend and pursue.
}

${ }^{20}$ She rejects Quine's claim that it is not sentences but utterances that might be definitional truth (related to the claim I defended above), insisting that it is sentence-types, like 'I am here now', that are (eternally) analytic. I have already pointed out the problems in this quotation: "analytic sentences, such as I am here now $\ldots$ are recognizably analytic because the reference determiners ensure that the sentence is true with respect to all contexts of utterance and contexts of introduction, and speakers may recognize that the sentence is analytic because those reference determiners are not forgotten by competent speakers: speakers have to know that $I$ refers to the agent of the context in order to be competent with the word" (156). Competence provides speakers with the character of 'I'; this is what they do not forget; and it may be (putting aside answering machines, etc) that the combined characters of the indexicals make it the case that the sentence-type is true with respect to all contexts of utterance and introduction. But merely the character does not determine the referent of any particular token of 'here', say; and speakers will easily forget any particular reference-determiner for it, so forgetfulness is irrelevant. 
ence-fixing stipulation $\mathrm{Sam}_{\mathrm{RF}}$; that again has to do with the wellestablished phenomenon of semantic deference, which we have already mentioned. However, Russell also says that reference-fixing stipulations such as $\mathrm{Sam}_{\mathrm{RF}}$ are "meaning-independent", because they can be replaced by other stipulations without changing the meaning of the name (155); and that claims such as 'Sam is the tallest boy in the class' are not analytic, because "if a giant joined Sam's class, we would be able to utter it falsely" (156). ${ }^{21}$ Let us critically examine these claims in reverse order.

In the first place, for the latter claim to be true we have to interpret the description without any specific temporal qualification. However, taken in that way, nobody in her right mind would use it to fix the referent of anything, because there is very little reason to think that it will be a proper description, uniquely satisfied. Thus, if it is to be a decent candidate for a reference-fixer, we should understand the description with the relevant qualifications about the class and time; otherwise, we should discuss well-known examples such as 'Julius' instead, whose reference is fixed with descriptions such as 'the inventor of the zip', plausibly taken to be proper without any qualification. Now, if precisified in the way suggested, Russell accepts that it would be analytic; but she still expresses some misgivings: "but then this definition $\left[\mathrm{Sam}_{\mathrm{RF}}\right]$ does more than ascribe a referent; it also (implicitly) ascribes a reference determiner" (p. 156). And so what? Is not this the case with all reference-fixing ascriptions? The question is whether an assertion of 'Julius invented the zip', or one of 'Sam is the tallest boy in the class', made on the assumption of the relevant reference-fixing stipulations (hence, in the latter case, with the description understood as precisified with regard to a salient class and time), is analytic; and Russell appears to concur, as she should, for sheer consistency with what has come before. Thus, firstly Quine appears to be right that it is not the sentence, but specific utterances of it, made in specific contexts, that are properly counted as analytic. And secondly, there is no additional ephemerality or transience in this case to that already found in the pet case of 'I am here now', when properly understood.

${ }^{21}$ The very same words 'Sam is the tallest boy in the class' can be used to make a stipulation such as $\mathrm{Sam}_{\mathrm{RF}}$, and to make a statement or assertion assuming the stipulation. The former is a proposal or an agreement, not properly evaluable as true or otherwise; only the latter can be properly counted as analytical, therefore. 
This disposes also of the other point, about the "meaning independence" of stipulations such as $\mathrm{Sam}_{\mathrm{RF}}$. Millians talk that way, because they are assuming that the meaning of names is just the referent; this is what they take to have learnt from Kripke. Russell has already convincingly shown that it is not meaning in that sense that analyticity can be properly predicated of; it has to be meaning in the sense of "reference-fixer" or "reference-determiner". I have argued that it is expressions-in-context that are relevant for ascriptions of analyticity, and not just in virtue of relative stable properties of the types, but also in virtue of more idiosyncratic, contextually dependent features. Thus, I do not think it is consistent with the view developed so far, nor intuitive at all, to say that the reference-fixing stipulation for 'Julius' is meaning-independent, in the sense of "meaning" relevant to analyticity claims: introducing a new stipulation would change the meaning of 'Julius', even if the new description determines the same referent. And the same applies to $\mathrm{Sam}_{\mathrm{RF}}$, when the relevant precisifications are made.

\section{The analytic, the a priori and the conventional}

Russell avoids trouble by putting aside the issue of whether the justification that analyticity might provide is a priori justification. There are three off-putting problems that she points out. Firstly, while the bearers of analyticity are linguistic items, those of aprioricity are objects of knowledge and belief, therefore propositions. Secondly, there is no good account of a priori knowledge: it is knowledge not depending on experience, even if experience has played an "enabling" role in its acquisition; but the distinction between the enabling and justificatory roles of experience is unclear. Finally, there is the Quinean issue of how much knowledge (of logic, in particular) is needed to derive anything from meaning-ascriptions. So, putting aside (not fully, as we will see) whether analytic justification is a priori or otherwise, she explores instead whether there is any distinctive kind of justification that analyticity might provide.

She comes up with an interesting suggestion. Knowledge of reference-determiner, together with disquotational knowledge, puts us in a position to acquire some knowledge through fairly basic inferential schemes. Thus, knowledge of reference determiner tells us that 'bachelor' applies only to males; disquotational knowledge tells us 
that 'bachelor' applies just to bachelors; and from this it is an easy inferential step to the non-linguistic, world-involving conclusion that all bachelors are males. In this final section I will discuss two considerations that Russell provides regarding why this sort of justification is interesting.

The first is that, notwithstanding her disclaimers, she points out that the justification is in a clear sense a priori: "anyone who knows the reference determiners for the expressions they [analytic sentences] contain is in a position to work out that the proposition expressed by the sentence is true, without undertaking further empirical investigation" (p. 209). Someone might contend that this is still a posteriori justification, because it crucially depends on knowledge of the ascription of reference-determiner, which is known from experience. Russell has an interesting point to make in reply: "'I could justify my belief that all bachelors are men using any language in which bachelor has the reference determiner which I thought it had in the English dialect - including my own idiolect, or a language fragment I make up" (p. 211); “you don't need experience to justify your beliefs about what words mean in your own idiolect - you get to stipulate them, as you go along if needs be" (p. 218). Presently I will be questioning her claims about stipulation in their full generality; however, the defender of the a priori character of knowledge gained through the kind of analytic justification that Russell describes can at the very least use her point about the relation between public language and one's own idiolect, insisting that whatever experience is required to understand one's own idiolect plays at most an enabling role in justification, in a sufficiently clear-cut sense to allow one to help oneself to the distinction in this particular case.

The second consideration I would like to discuss is this: "The truth of such attributions [of reference determiners] is, to a large extent, up to the linguistic community to decide" (p. 209). We just saw the importance she assigns to this alleged stipulative character of ascriptions of reference determiner in her (reluctant) vindication of the $a$ priori nature of analytic justification. Now, a successful stipulation is in a clear sense a convention; so she sounds here as if she is not just 
purporting to vindicate metaphysical analyticity - truth in virtue of meaning - but also truth by convention. ${ }^{22}$

This is a central issue addressed by García-Carpintero \& PérezOtero (2009). They argue not only in favor of metaphysical analyticity, but also of truth by convention, in some very limited sense, as follows: (i) after we stipulate that 'flurg' is to apply to green squares, 'all flurgs are green squares' is an interpreted sentence that semantically differs from 'all green squares are green squares', in that it includes a distinctive lexical item for green squares, thereby indicating that they constitute a salient kind for some purposes; (ii) modulo the analyticity of 'all green squares are green squares', 'all flurgs are green squares' is analytic (in a sense very similar to Russell's, in that its truth results from an ascription of reference-fixer); (iii) it is a partially conventional truth (and would be fully conventional if 'all green squares are green squares' were not just analytic, but true by convention), because that ascription of reference-fixer is a convention. Similar points are made about 'Manolo is identical to Manuel': it differs from 'Manuel is identical to himself', in that it depends on a specific stipulation making an expression ('Manolo') anaphoric on another, unlike 'Manuel is identical to himself' which is just the natural-language instantiation of the reflexivity of identity; it is an analytic truth, if instances of $a=a$ are; it is partially conventional, and fully conventional if the latter are.

However, even though they thus vindicate conventional truth in this limited sense, they argue that the vindication is very limited. Although, they argue, 'water falls from the sky' or 'water fills up the rivers, lakes and seas around' are also analytic in the relevant sense (something that, I argued in sections 2 and 4 above, Russell does not appear to like, but does follow from her account in terms of reference-determiner once the misunderstandings about bearers of analyticity, character and reference determiners are cleared up), ${ }^{23}$ they contend that the reference-fixing ascriptions on which they depend,

\footnotetext{
${ }^{22}$ But I cannot be sure, because the matter is not fully addressed in the book; we are just given several references to the role of stipulation, without further elaboration.

${ }^{23}$ The a priori nature of those claims can also be defended along the lines she herself neatly indicates, with the modification I have suggested above to avoid reliance on stipulations, given that I do not believe that the relevant reference-fixing ascriptions have that character in this case.
} 
unlike those for 'flurg' (or 'bachelor') cannot be considered in any way conventional or stipulative. Lexical units such as 'water' are intended to pick out kinds that are salient because they are natural; and it is not at all conventional that we fix reference to them by means of those of their features relatively accessible to us that are to be explained by whatever constitutes the essence of the kind. An indication of this (defeasible, but undefeated in this case, I would argue) is that, while it is not to be expected that many linguistic communities have a lexical item for green squares, the opposite can be said about the substance that falls from the sky and fills up rivers, lakes and seas. Although the issue of logic or mathematics is more complicated, we suggest that it is prima facie more sensible to classify them with the claim about water than with the claim about flurgs. Thus, although - against Boghossian - not just the notion of metaphysical analyticities but also that of conventional truths is intelligible, and indeed there are examples of both, critics of conventionalism are right when it comes to interesting topics, such as logic or arithmetic.

My final critical comment is that, at the very least, the claims about the stipulative character of analyticities bear more elaboration. The inspiration for thinking further about them would be one of the many benefits of the close study of this thought-provoking and necessary book.

Manuel García-Carpinter Departament de Lògica, Història i Filosofia de la Ciència

Universitat de Barcelona e-mail:m.garciacarpintero@ub.es

\section{References}

Boghossian, Paul (1997): "Analyticity”, in B. Hale and C. Wright (eds.) A Companion to the Philosophy of Language, Oxford: Blackwell, 331-368.

Egan Andy (2009): "Billboards, Bomb and Shotgun Weddings", Synthese 166, 251279.

Fine, Kit (1994): "Essence and Modality," in Philosophical Perspectives 8, Logic and Language, J. Tomberlin (ed.), Atascadero, Cal.: Ridgeview.

García-Carpintero, Manuel (1998): "Indexicals as Token-Reflexives", Mind 107 (1998), pp. 529-563.

García-Carpintero, Manuel (2000): “A Presuppositional Account of ReferenceFixing,” Journal of Philosophy XCVII (3), 109-147. 
García-Carpintero, Manuel (2006a): "Recanati on the Semantics/Pragmatics Distinction," Crítica 38, 35-68.

García-Carpintero, Manuel (2006b): “Two-dimensionalism: a Neo-Fregean Interpretation”, in García-Carpintero, M. \& Macià, J. (eds.), Two-Dimensional Semantics, Oxford: Oxford University Press, 181-204.

García-Carpintero, M. \& Pérez-Otero, M. (2009): "The Conventional and the Analytic", Philosophy and Phenomenological Review 78: 239-27.

Kaplan, David (1989): "Demonstratives", in J. Almog, J. Perry and H. Wettstein (eds.), Themes from Kaplan, Oxford: Oxford University Press, 481-563.

Williamson, Timothy (2007): The Philosophy of Philosophy, Oxford: Blackwell. 